\title{
Venoz Tromboemboli Tedavisinde Yeni Kılavuz Işı̆̆ında Güncelleme
}

Mehmet Kalender, Mustafa Canikoğlu

Sağlık Bilimleri Üniversitesi Derince Eğitim ve Araştırma Hastanesi, Kalp ve Damar Cerrahisi Kliniği, Kocaeli, Türkiye

Iletişim / Correspondence:

Doç. Dr. Mehmet Kalender

Sağlık Bilimleri Üniversitesi Derince Eğitim ve Araștırma Hastanesi,

Kalp ve Damar Cerrahisi Kliniği, Kocaeli, Türkiye

E-mail:rukiye.boluktas@izu.edu.tr

Başvuru Tarihi: 01.02.2021

Kabul Tarihi: 23.03.2021

Venöz tromboemboli (VTE) dünya çapında 100000 ' de 30-50 oranında görülen, hastane yatışına bağlı ölümlerin en sık sebebi olan ciddi mortalite ve morbidite oranına sahip bir durumdur. Derin ven trombozu (DVT) ve pulmoner embolinin (PE) finansal yükü hastanın yatarak tedavi edilip edilmediğine, yeniden başvuru oranına, hastalığın progresine ve komplikasyonlara bağlı olarak değişmektedir (1). Son yıllarda hem tanı yöntemlerinin gelişmesi ve tedaviye ulaşılabilirliğin artmasına ve hem de onkolojik hastalıkların ve/veya major cerrahi girişimlerin artmasına rağmen VTE insidansında artış görülmemektedir (2). Bunun olası sebebi VTE önleme ve baş etme yöntemlerinin başarısıdır.

2014 yılında yayınlanan klavuza göre tedavi 5 gün parenteral (LMWH) antikoagulasyon ve ardından vitamin $\mathrm{K}$ antagonisti (warfarin) (VKA) ile hedef INR 2 olacak şekilde en az 3 ay tedavidir (3). Ancak warfarin'in dar törapatik aralı̆̆ı, diğer ilaçlarla etkileşimi, diyetteki değişikliğin ilaç etkinliğini değiştirmesi, yavaş etki başlangıcı ve etkinin geç kaybolması gibi sorunların yanında ayrıca warfarin kullanımıyla kanama riskinde artış, süregelen INR monitorizasyonu ve doz ayarlama gerekliliği sebebiyle maliyetli ve riskli bir tedavidir $(3,4)$.
Doi: $10.5505 / \mathrm{ktd} .2021 .74507$

Mehmet Kalender: 0000-0002-8984-4028

Mustafa Canikoğlu: 0000-0001-9392-4525
Warfarin 'in yukarıda sayılan handikapları sebebiyle yeni nesil antikoagulan ilaçlara ihtiyaç duyulmuştur. İlk olarak VTE tedavisinde 2012 yılında k1lavuzda yer bulan yeni nesil oral antikoagulanlar (YOAK) yıllar içerisinde daha iyi tanınır ve yaygın olarak kullanılır hale geldi(5). 2021 yılinda ESVS (European Society for Vascular Surgery) yeni bir rapor yayınlarak VTE tedavisini güncelledi (6). Bu haliyle güncel kılavuz 1şı̆ğında DVT tedavisi aşağıda özetlenmiştir.(Şekil 1, Şekil 2)

\section{Risk faktörlerine örnekler:}

Geçici major risk faktörleri: genel anestezi altında 30 dakikadan uzun süren cerrahi, 3 günden uzun süren hastane yatışına sebep olan akut hastalıklar, sezaryan, östrojen terapisi, hamilelik veya lohusalık.

Geçici minor risk faktörleri: genel anestezi altında 30 dakikadan kısa süren cerrahi, 3 günden az süren hastane yatışına sebep olan akut hastalıklar, hastane dışında 3 günden uzun süren yatak istirahatine neden olan akut hastalıklar, en az 3 gün azalmış mobilitiye sebep olan bacak sakatlığı. Sabit risk faktörleri: kanser, inflamatuar barsak hastalıkları 


\section{Sekil 1: Altta yatan sebebi bulunan hastalarda yaklașım}

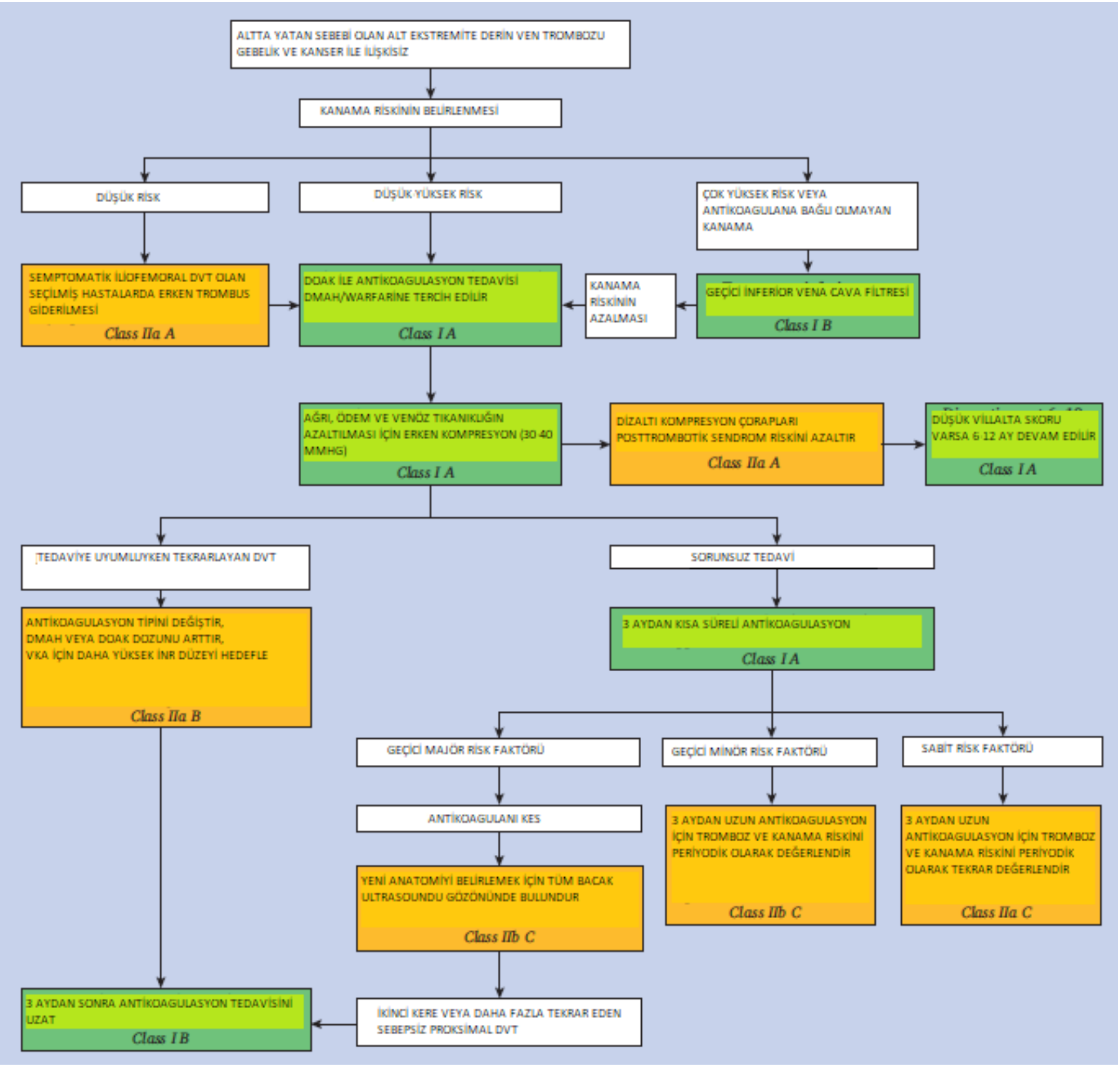




\section{Sekil 2: Altta yatan sebebi bulunmayan hastalarda yaklassm}

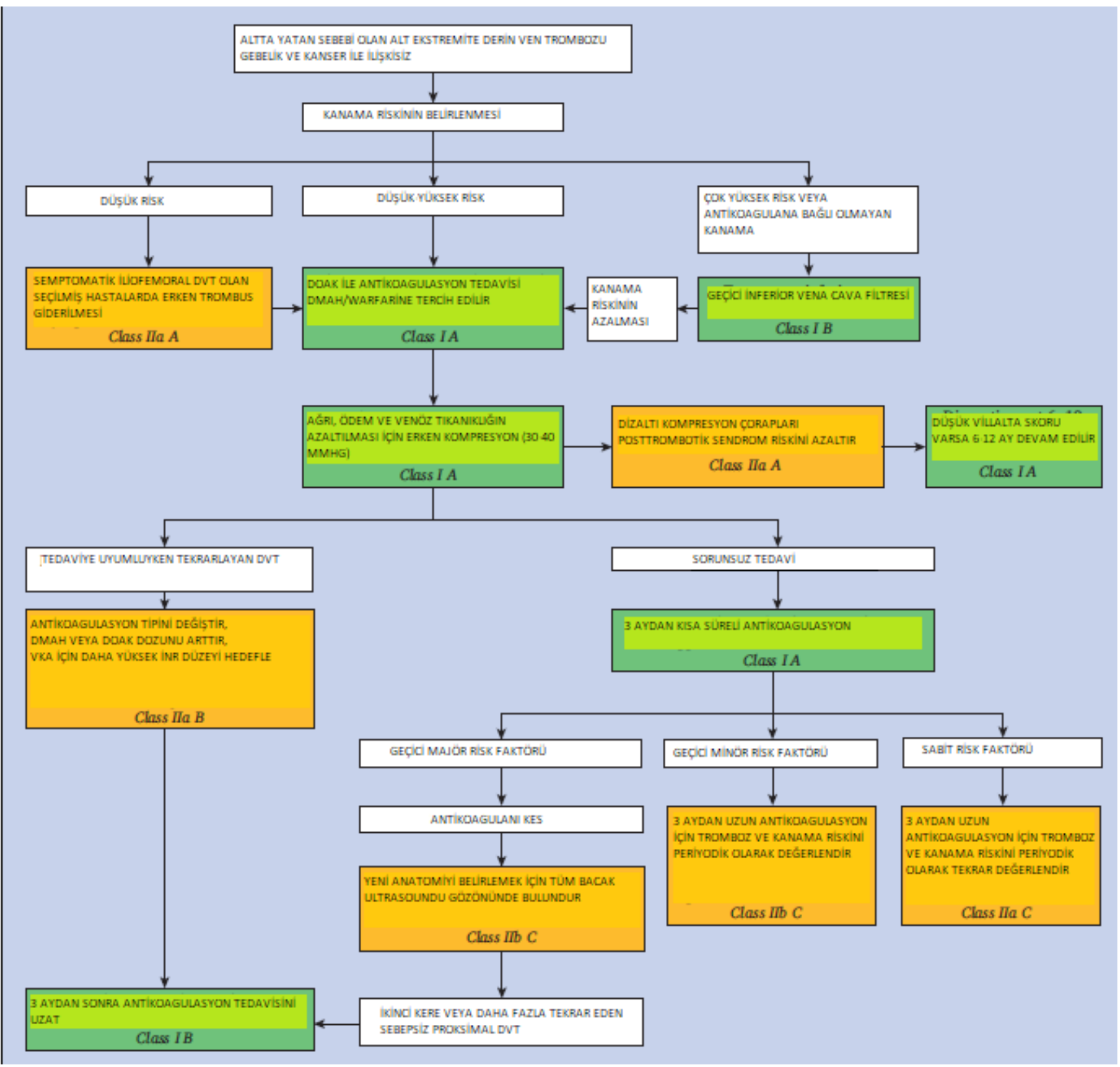

Etik Kurul Onayı: Etkkunulu onay formuna gerek yotur.

çkar Çatışması: Yazarlar herhangi bir gkkar çatşsması olmadı̆nı beyan eder.

Finansal Destek Fnansal destek yoktur.

Hasta Onamc Hastalardan onamalnmıştr. 


\section{KAYNAKLAR}

1. Barco S, Woersching AL, Spyropoulos AC, Piovella F, Mahan CE. European Union-28: an annualised cost-of-illness model for venous thromboembolism. Thromb Haemost. 2016;115:800e8.

2. Heit JA, Ashrani A, Crusan DJ, McBane RD, Petterson TM, Bailey KR. Reasons for the persistent incidence of venous thromboembolism. Thromb Haemost. 2017;117:390e400.

3. January CT, Wann LS, Alpert JS, Calkins H, Cigarroa JE, Cleveland JC Jr, et. al. American College of Cardiology/American Heart Association Task Force on Practice Guidelines. 2014 AHA/ACC/HRS guideline for the management of patients with atrial fibrillation: a report of the American College of Cardiology/American Heart Association Task Force on Practice Guidelines and the Heart Rhythm Society. J Am Coll Cardiol. 2014 Dec 2;64(21):e1-76. doi: 10.1016/j.jacc.2014.03.022. Epub 2014 Mar 28. Erratum in: J Am Coll Cardiol. 2014 Dec 2;64(21):2305-7. PMID: 24685669.

4. Çelik A, İzcil $S$, Kobat $M$ A, Ateş H A, Çakmak A, Çakıllı Y, Yılmaz M B. The awareness, efficacy, safety, and time in therapeutic rangeof warfarin in the Turkish population: WARFARINTR Anatol J Cardiol. 2016; 16: 595-600.

5. Kearon C, Akl EA, Comerota AJ, Prandoni P, Bounameaux H, Goldhaber SZ, et al. Antithrombotic therapy for VTE disease: antithrombotic therapy and prevention of thrombosis, 9th ed: American College of Chest Physicians Evidence-Based Clinical Practice Guidelines. Chest. 2012;141. e419Se96S.

6. Kakkos SK, Gohel M, Baekgaard N, Bauersachs R, Bellmunt-Montoya S, Black SA, et. al. Editor's Choice - European Society for Vascular Surgery (ESVS) 2021 Clinical Practice Guidelines on the Management of Venous Thrombosis. Eur $\mathbf{J}$ Vasc Endovasc Surg. 2021 Jan;61(1):9-82. doi: 10.1016/j.ejvs.2020.09.023. Epub 2020 Dec 15. PMID: 33334670.

ed 2020; 8(3):220-22. 